\title{
Update from RCP Quality Improvement: making quality improvement mainstream for physicians and teams
}

From this issue onwards, this part of the Future Healthcare Journal is where you will find regular updates on the work RCP Quality Improvement.

We very much welcome your feedback. If you have any comments, or would like to be involved in the work of RCPQI, please contact RCPQI@rcplondon.ac.uk.

In this journal in 2016 the launch of the Royal College of Physicians' (RCP's) Quality Improvement Hub was reported, along with the rationale for this. 'More recently, the final report on the RCP's Future Hospital Programme, Delivering the Future Hospital, identified that there is a need for the RCP to support service improvement much more widely, in a way which is patient-centred and physician-led. ${ }^{2}$

Professional societies like the RCP have an important role in making quality improvement a core part of professionalism. This should be done through:

> consistent messaging, policy and advocacy

$>$ working with others to embed quality improvement activity into the medical curriculum at undergraduate and postgraduate levels ${ }^{3}$

$>$ developing an expectation of quality improvement activity within appraisal and revalidation and the development of supportive tools and documentation for this

> linking with and supporting other professional bodies and national and regional organisations

> supporting healthcare practitioners and their team members to deliver quality improvement in practice.

Following a period of initial exploration and development, the RCP Quality Improvement Hub has become RCP Quality Improvement (RCPQI). It is now building on the considerable learning of the Future Hospital Programme to support physicians and their teams to deliver improvements in services and the quality of patient care. $\mathrm{RCPQI}$ aims to:

$>$ improve patient care by building capacity throughout the healthcare workforce to implement continuous improvement and change

> develop leadership skills within healthcare teams that will sustain improvement across the NHS

$>$ directly support organisations to meet their improvement goals by pairing them with clinical improvement experts

> support the testing, evaluation and dissemination of new improvement methodologies.

Other royal colleges and professional societies are also supporting their members in a similar way. For example, the Royal College of
General Practitioners (RCGP) has developed QI Ready (www.rcgp. org.uk/qi-ready), an online tool to assist GPs to better understand quality improvement and use methodologies. It includes an online learning network and a series of learning modules. The RCGP has also produced the Quality Improvement Guide for General Practice and is piloting a growing list of quality improvement approaches in practice. ${ }^{4}$ From August 2016, the Royal College of Emergency Medicine implemented an assessment system within the training structure, which includes the requirement for trainees to complete a quality improvement project. ${ }^{5}$ The professional bodies supporting renal care have come together to form KQuIP (www.thinkkidneys.nhs.uk/kquip) with the aim of embedding systematic quality improvement into everyday multidisciplinary practice.

Clinicians may need different types of skills to deliver service improvements, depending on the level of complexity. These broadly sit at four levels:

> large-scale change and population-level strategic changes

$>$ service design and improvement within and across pathways

$>$ process improvements within current services

$>$ day-to-day problem solving.

In Scotland and Wales a more nationally coordinated approach has been taken to developing quality improvement skill and practice and embedding them within the NHS system. The Scottish Quality and Safety (SQS) Fellowship Programme has now trained and supported over 200 clinicians in developing their quality improvement skills, practice and leadership. ${ }^{6}$ The Improving Quality Together programme in Wales (www.1000livesplus.wales.nhs.uk/iqt), part of the 1,000 lives campaign, has trained and supported more than 3,000 clinicians across the country to three levels of expertise in quality improvement practice. In England, NHS Improvement's publications Developing people, improving care and Building capacity and capability for improvement: embedding quality improvement skills in NHS providers set a clear direction for NHS organisations to develop their quality improvement capacity in staff. ${ }^{7,8}$ So quality improvement is rapidly moving from being seen as a niche area for a small number of 'fanatics' to being a mainstream part of professionalism for many clinical and managerial professionals within healthcare, and the work of all healthcare staff.

It is important to note that other mechanisms that improve quality of care are complemented by quality improvement, which focuses on implementing change using evidence-based approaches. So clinical standards, clinical guidelines, clinical education, non-technical skills education, clinical audit, peer review, team leadership development, technological innovation, data analysis, and of course research all have an essential part to 


\begin{tabular}{|c|c|c|c|c|c|}
\hline $\begin{array}{l}\text { Building } \\
\text { capacity } \\
\text { Equip the } \\
\text { healthcare } \\
\text { workforce } \\
\text { with skills and } \\
\text { expertise to } \\
\text { continuously } \\
\text { improve } \\
\text { services }\end{array}$ & $\begin{array}{l}\text { Collaboratives } \\
\text { 9-month, topic } \\
\text { specific quality } \\
\text { improvement } \\
\text { course for } \\
\text { clinicians and } \\
\text { their teams }\end{array}$ & $\begin{array}{l}\text { Virtual hub } \\
\text { Connecting } \\
\text { people, best } \\
\text { practice, tools } \\
\text { and evidence }\end{array}$ & $\begin{array}{l}\text { Leadership for } \\
\text { improvement } \\
\text { Develop medical } \\
\text { leaders who can } \\
\text { influence and } \\
\text { embed a culture } \\
\text { of quality and } \\
\text { continuous } \\
\text { improvement }\end{array}$ & $\begin{array}{l}\text { Research and } \\
\text { development } \\
\text { Develop, adapt, } \\
\text { design new } \\
\text { improvement } \\
\text { methods and } \\
\text { knowledge }\end{array}$ & $\begin{array}{l}\text { Bespoke } \\
\text { support } \\
\text { Provide expert } \\
\text { assessment and } \\
\text { support in } \\
\text { tackling } \\
\text { particular } \\
\text { organisational } \\
\text { and service } \\
\text { challenges }\end{array}$ \\
\hline
\end{tabular}

Fig 1. Royal College of Physicians Quality Improvement (RCPQI). RCPQI aims to make quality improvement easily accessible to all doctors and support physicians in developing and providing safe, timely, evidence-based, efficient and patient-centred care to achieve the RCP's strategic aim of improving quality. The work is delivered through six workstreams, supported by a faculty of quality improvement experts.

play in improving quality, but without successful implementation in practice will have less impact. Furthermore, quality assurance must be in place to know how well we are doing, and which areas to focus on for improvement. This is why organisations such as the RCP that have functions to support many of these areas are uniquely placed to support the development of quality improvement practice in clinical teams, and to integrate it with these other components of the quality jigsaw.

The RCP's journey into quality improvement arguably began with the development of the Learning to Make a Difference Programme, which was set up to support core medical trainees undertaking quality improvement projects and their supervisors. ${ }^{9}$ In addition, a number of the national clinical audits supported some quality improvement activity, and RCP Education ran some training workshops. These elements are being expanded and have been incorporated into RCPQI's growing programme, which is shown in Fig 1.

There is a rapidly growing number of physicians across the UK who have significant skills and experience in leading and delivering quality improvement programmes. Fifty-four of these individuals have committed to join the RCPQI Faculty, supported by their employers, and the RCP has committed to support their further development.

Most of the changes in the way we deliver care require multiprofessional working across health and care systems. RCPQI's programme will therefore be delivered in partnership with other professional and patient groups and will emphasise the needs of populations and systems wherever possible.

Medical undergraduates are increasingly undertaking quality improvement projects as part of their training, and quality improvement projects are now part of the post graduate curriculum for most specialities. So new generations are rapidly developing their skills and practice in this area, and expect to use and further refine these throughout their careers.

As with all areas of practice, new knowledge and new evidence continues to be developed in quality improvement. Engineering better care was the joint work of the RCP, the Royal Academy of Engineers and the Academy of Medical Sciences, and describes a framework to develop and incorporate new ways of designing and improving health and care. ${ }^{10}$ The THIS institute (www.thisinstitute. cam.ac.uk) has been established in Cambridge and will evaluate the effectiveness of improvement approaches and interventions.
Quality improvement is now mainstream for clinical professionals and the RCP will play a significant role in supporting professional development and delivery, in discovering new practice in quality improvement, and disseminating through its publications, including Future Healthcare Journal.

John Dean

Clinical director for quality improvement and patient safety, Royal College of Physicians

\section{References}

1 Choudry MI, Stewart K, Woodhead T. The Royal College of Physicians Quality Improvement Hub - how can it help physicians to improve patient care? Future Hosp ] 2016;211-6.

2 Royal College of Physicians. Delivering the Future Hospital. London: RCP, 2017. www.rcplondon.ac.uk/projects/outputs/future-hospitalprogramme-delivering-future-hospital [Accessed 16 May 2018].

3 Academy of Medical Royal Colleges. Quality Improvement training for better outcomes. London: AoMRC, 2016.

4 Royal College of General Practitioners. Quality improvement guide for general practice. London: RCGP, 2015. www.rcgp.org.uk/clinicaland-research/our-programmes/quality-improvement/qualityimprovement-guide-for-general-practice.aspx [Accessed 16 May 2018].

5 Royal College of Emergency Medicine. RCEM Quality Improvement Guide. London: RCEM, 2016.

6 NHS Education for Scotland. Scottish Quality and Safety (SQS) Fellowship Programme. https://learn.nes.nhs.scot/814/qualityimprovement-zone/learning-programmes-leader/scottish-qualityand-safety-sqs-fellowship-programme [Accessed 16 May 2018].

7 NHS Improvement. Developing people - improving care. https:// improvement.nhs.uk/resources/developing-people-improving-care [Accessed 16 May 2018].

8 NHS Improvement. Building capacity and capability for improvement: embedding quality improvement skills in NHS providers. https://improvement.nhs.uk/resources/embedding-quality-improvement-skills [Accessed 16 May 2018].

9 Vaux E, Went S, Norris M et al. Learning to make a difference: introducing quality improvement methods to core medical trainees. Clin Med 2012;12:520.

10 NHS Improvement. Engineering better care: a systems approach to health and care design and continuous improvement. https:// improvement.nhs.uk/resources/engineering-better-care-systemsapproach-health-and-care-design/ [Accessed 16 May 2018]. 